\title{
Mindfulness and academic resilience among unprivileged college students: The mediating role of self-compassion
}

\author{
Hanan Salsabila, Pratiwi Widyasari \\ Faculty of Psychology, Universitas Indonesia, Indonesia \\ Corresponding author: hanan.salsabila@ui.ac.id
}

\section{ARTICLE INFO}

Article history

Received December 16, 2020

Revised June 8, 2021

Accepted July 27, 2021

Keywords

academic resilience;

college student;

mindfulness;

self-compassion

unprivileged student.

\begin{abstract}
A growing body of studies shows that the higher individuals' education level, the higher their chance of getting a better salary. Unfortunately, for unprivileged students who want to improve their living conditions, the risk of failure to complete college is much higher because of numerous obstacles regarding their economic status. Having good academic resilience may foster unprivileged college students to achieve success in their studies. This study aimed to find out the relationship between mindfulness and academic resilience with self-compassion as a mediator. One hundred thirtyone unprivileged college students participated in this cross-sectional, quantitative study. Three adapted scales were used: (1) The Mindfulness Attention Awareness Scale (MAAS), (2) The SelfCompassion Scale (SCS), and (3) The Academic Resilience Scale (ARS-30). The data were then analyzed with the Hayes Regression technique. The findings support the hypothesis that self-compassion fully mediates the relationship between mindfulness and academic resilience among unprivileged Indonesian college students with a 23.1 percent contribution. Therefore, among unprivileged students, the impact of mindfulness on academic resilience will be higher through self-compassion.
\end{abstract}

\section{Introduction}

Almost everyone shares the desire to actualize their dreams and live a better life, and one of the ways is through earning a degree in college. Unfortunately, college learning experiences are more complicated than previous education levels. In college, students are demanded to solve problems by conducting research, analyzing various conflicting data, proposing arguments and explanations using facts, and drawing conclusions (National Research Council, 2002). Moreover, a college learning environment expects students to be independent problem-solvers who collaborate with other students and seek help whenever experiencing academic difficulties (National Survey of Student Engagement, 2006).

Even though it is difficult, finishing college is an essential thing to achieve. Research shows that the higher a person's education level, the better their income (Jerrim \& Macmillan, 2015). Therefore, education is a primary way to improve one's economic situation (Salam, Awang Iskandar, Ibrahim, \& Farooq, 2019). Unfortunately, for unprivileged individuals who want to improve their living conditions, the chances of obtaining tertiary education are somewhat smaller (Duncan \& Magnuson, 2013). Even if these unprivileged students get the opportunity to go to college, they have a greater risk of failing to complete their studies (Cahalan et al., 2020; Engle \& Tinto, 2008). In the future, this failure will affect their chances of getting a job. They tend to get jobs with low salaries 
or become unemployed because they do not have adequate skills (unskilled labor).

For unprivileged students, the risk of failure to complete college occurs due to obstacles caused by economic difficulties (Cilesiz \& Drotos, 2016). The high cost of tertiary education impacts the gross tertiary enrollment ratio of students from lower economic backgrounds. Ideally, law 12/2012 states that 20 percent of tertiary education students in Indonesia should come from low-income families. However, only 10 percent of college students are (World Bank, 2014). Aside from having difficulty paying tuition fees, a financial shortage makes unprivileged students often take on other obligations, such as working to meet their families' needs (Engle \& Tinto, 2008). Extra busyness reduces the opportunity to be involved in many academic and social activities on campus to facilitate college success (Engle \& Tinto, 2008). They also find it challenging to pay for additional books, technologies, and tutoring to support better academic performance. Furthermore, socially, unprivileged students feel less confident interacting with regular students (Cilesiz \& Drotos, 2016). They tend to feel intimidated, uncomfortable, and isolated (Aries \& Seider, 2005). This situation may occur because of the vast differences between the college environment and their living conditions and values. Hence, the Indonesian government has provided a solution for unprivileged students by offering scholarships. However, considering the whole situation, other solutions are also necessary, such as creating a college system that allows unprivileged students to be actively involved in their studies, support groups, finances management classes, and programs that help increase academic persistence (Engle \& Tinto, 2008). Therefore, a study on factors that support the development of academic resilience is needed to construct college programs that are helpful for unprivileged students (Masten, 2014).

All students will face challenges during college, but some perform poorly, while others that have good resilience will thrive despite adversities (Martin \& Marsh, 2006). Resilience in the context of education is defined as a person's ability to overcome academic difficulties to achieve academic success, also known as academic resilience (Cassidy, 2016). Cassidy (2016) explains that academic resilience could be measured based on adaptive and nonadaptive responses (cognitive, affective, and behavioral) shown when students face academic difficulties. Cassidy (2016) divides the response into three dimensions, namely: (1) reflecting and adaptive help-seeking, (2) perseverance, and (3) negative affect and emotional response. Based on Cassidy's (2016) dimensions, less resilient students will show an attitude of giving up easily, are less able to reflect on their capability and performance to find the help needed, and have difficulty managing negative emotions. In other words, students with poor academic resilience will show insufficient determination and effort to achieve success in their educations compared to students with good academic resilience.

According to Richardson (2002), someone who demonstrates good resilience has stronger protective factors that buffer the negative impact of the risk factors (adversities). These protective or risk factors could come from external (e.g., supportive family, unsupportive family) or internal factors such as personality or psychological resources (Ledesma, 2014). For unprivileged students, external factors, which are their living conditions and experiences, tend to weaken their resilience (Evans \& Kim, 2013). Chen \& Matthews (2001) explain that this happens because the experience of growing up in a stressful, violent, and unstable environment makes individuals develop negative cognitive biases. Individuals raised in poverty tend to be accustomed to negatively interpreting situations. For example, a poor student who does a presentation and sees a friend smiling at him could immediately feel anxious because they associate this attitude as mocking at their bad performance (Chen \& Matthews, 2001). Neuroscientifically, Javanbakht et al. (2015) explain that living in poverty causes a person's amygdala to be more reactive. The amygdala 
is a part of the brain known to be associated with anxiety and fear. Therefore, it is crucial to pay attention to the effect of this external factor (environment condition), so these unprivileged students are not easily stressed and give up on college challenges. Several studies show that mindfulness is an internal factor that could reduce reactivity in a person's amygdala and strengthen their resilience (Rogers, 2013; Taren et al., 2015).

Mindfulness is a concept that comes from Buddhism, which says that humans have a tendency to get lost in the past or rush into the future; two frameworks of time that are not in the grip or power of self (Shonin, Van Gordon, \& Griffiths, 2014). Mindfulness is a flexible state of consciousness characterized by attention and awareness without judging present experience (Brown \& Ryan, 2003). Attention is a radar that continuously monitors the situation inside and outside oneself, while awareness is the ability to focus the attention based on needs without judging the experiences. Mindfulness teaches individuals to stop control and choose to acknowledge the presence of thoughts and feelings that arise (Bishop et al., 2004). Mindfulness improves the quality of one's consciousness. As a concept, mindfulness can be viewed as a state or a trait. As a state, mindfulness is a condition that is temporary and occurs when a person practices mindfulness exercises such as meditation (Lau et al., 2006), while mindfulness as a trait is more stable over time and considered a part of one's personality (Brown \& Ryan, 2003). However, recent research has found that repeated meditation practice (state of mindfulness) can positively affect mindfulness as a trait (Nyklíček, Dijksman, Lenders, Fonteijn, \& Koolen, 2014). This finding shows that personality is a condition that can still change. Individuals can adjust themselves according to the feelings, beliefs, and actions they choose. This study itself wants to examine mindfulness as a trait or a stable capacity to be more aware and attentive to the present moment without passing judgment.

Increased awareness caused by mindfulness enables a person to act without being impulsive or defensive when faced with unpleasant conditions (Niemiec, 2005) and developing the insights needed to take appropriate actions (Brown, Ryan, \& Creswell, 2007). According to research, mindfulness and acceptance of a condition boost individual resilience, preventing recurring and depressive thoughts (Thompson, Arnkoff, \& Glass, 2011). Mindfulness helps reduce anxiety so that individuals can maintain a problem-solving approach to find workable solutions (Verplanken \& Fisher, 2014). In college, mindfulness help students adjust to the learning environment (Ramler, Tennison, Lynch, \& Murphy, 2016), reduce anxiety (Yamada \& Victor, 2012), increase concentration (Mapel, 2012), generate habits, and better study planning abilities (Broderick \& Jennings, 2012), reduces stress and improves psychological well-being (Galante et al., 2018). Therefore, we could conclude that mindfulness contributes to a better ability to face challenges, achieve college success, or improve academic resilience. Nevertheless, the fact about the relationship between mindfulness and academic resilience, there are some inconsistencies. Some studies state that the relationship between the two is strong or moderate, while others find it is weak (Benada \& Chowdhry, 2017; Keye \& Pidgeon, 2013; Mathad, Pradhan, \& Rajesh, 2017; Sünbuil, 2019). Therefore, it is essential to study a more definite mechanism between the two. Based on the literature study, self-compassion may shed light on the effect of mindfulness on academic resilience.

Previous studies show that the greater self-compassion someone has, the greater his resilience will be (Barnard \& Curry, 2011; MacBeth \& Gumley, 2012; Neff \& McGehee, 2010). When confronted with personal shortcomings, failures, mistakes, and painful situations in life, self-compassion entails treating oneself with kindness (Neff, 2003). Selfcompassion comprises three major components: self-kindness, feelings of common humanity, and mindfulness (Neff, 2003). When faced with suffering, self-kindness is an act 
of caring for and understanding oneself (Neff, 2011). The realization that failure or suffering is a part of being human is common humanity (Neff, 2011). Last but not least, being mindful in self-compassion entails being aware of suffering without ignoring or ruminating. Instead, someone could present the situation in a clear and balanced manner (Brown \& Ryan, 2003).

Self-compassion could help students face academic failure with a warmer, accepting, and loving attitude so they will forgive and let go of their failures easily and are more motivated to improve their performance (Breines \& Chen, 2012). Self-compassion also helps students facing academic challenges reduce excessive reactions and negative emotions (Leary, Tate, Adams, BattsAllen, \& Hancock, 2007). They become more accepting, put problems into the proper perspective, and realize their responsibility. In unprivileged adolescents, self-compassion can help them not treat themselves harshly when facing various negative and challenging experiences related to their economic status (Sünbül, 2019). Therefore, it can be concluded that the warmth provided by self-compassion makes it easier for individuals to rise from various difficulties and try again.

Self-compassion is closely related to mindfulness (Neff, 2003). These two constructs have a very similar mechanism, which includes the ability to deal with painful experiences with an accepting attitude that reduces the negative or reactive impacts that can occur (Neff \& Dahm, 2015). Previous research has also shown that the two constructs strongly correlate (Baer, Lykins, \& Peters, 2012). Nevertheless, some differences need to be addressed between mindfulness and self-compassion. Mindfulness, in general, is applied to any situation, whereas self-compassion is more focused on the situation that causes individuals to suffer (Germer, 2009). As a result, one can practice mindfulness in everyday activities like eating, drinking, and walking without self-compassion. Furthermore, self-compassion is a broader concept than mindfulness because it includes self-kindness and common humanity, the attitude of treating oneself with warmth, and realizing that oneself is not alone in those difficulties (Neff \& Dahm, 2015). Therefore, when faced with adversities, a person could be aware of the pain he is experiencing (mindfulness) without actively trying to soothe and treating oneself with warmness while also reminding oneself that adversity is a normal part of human life (self-compassion).

In Indonesia, several studies have investigated the benefits of mindfulness and selfcompassion among college students. These studies show self-compassion proved to improve college students' life satisfaction (Anggraeni \& Kurniawan, 2012) and self-efficacy (Madita \& Widyasari, 2020). Therefore, both variables are psychologically beneficial for college students' mental health. Nevertheless, none of the previous research explored the relationship between mindfulness, self-compassion, and academic resilience, especially in unprivileged college students in Indonesia. Therefore, this study fills the knowledge gap by focusing on unprivileged students who are a high-risk population. This study identifies attributes and conditions that affect academic resilience in unprivileged students, so universities can help strengthen this to support their academic success (Morales, 2014). The findings of this study can be used to create self-development programs in college (Wahyudi, Suardiman, \& Rosada, 2020). This study aimed to examine the role of self-compassion in mediating the relationship between mindfulness and academic resilience among unprivileged college students. This study hypothesizes that self-compassion mediates the relationship between mindfulness and academic resilience.

\section{Method}

This research is a quantitative, non-experimental, and cross-sectional study. The 
questionnaire was created using Google Form and distributed through Instagram and Twitter. Before participants fill out the questionnaire, the researchers provide a page containing the study's objectives and informed consent.

\section{Participants}

Students who could participate in this study are at least in their second semester of college, assuming they have experienced enough experience and challenges. Regarding the participants' economic status, there is no absolute standard to classify it due to differences in the cost of living and income in Indonesia's regions. Therefore, the researchers screened the participants using student characteristics allowed by the government to enroll in the government scholarship. Table 1 shows the demographic of participants in this study.

Table 1

Demographics of Participants

\begin{tabular}{|c|c|c|c|}
\hline \multicolumn{2}{|l|}{ Category } & Frequency & Percentage $(\%)$ \\
\hline \multicolumn{4}{|l|}{ Gender } \\
\hline & Male & 25 & 19.1 \\
\hline & Female & 106 & 80.9 \\
\hline \multicolumn{4}{|l|}{ Age } \\
\hline & Adolescent (17-19 years old) & 33 & 25.2 \\
\hline & Early Adulthood (20-27 years old) & 98 & 74.8 \\
\hline \multicolumn{4}{|c|}{ College year } \\
\hline & First Year (2nd Semester) & 3 & 2.3 \\
\hline & Second Year (3rd \& 4th Semester) & 35 & 26.7 \\
\hline & Third Year (5th \& 6th Semester) & 36 & 27.5 \\
\hline & Fourth Year (7th \& 8th Semester) & 48 & 36.6 \\
\hline & Fifth Year (9th \& 10th Semester) & 8 & 6.1 \\
\hline & Sixth Year (11th \& 12th Semester) & 1 & .8 \\
\hline \multicolumn{4}{|l|}{ University } \\
\hline & Public University & 97 & 74 \\
\hline & Private University & 33 & 25.2 \\
\hline & None & 1 & .8 \\
\hline \multicolumn{4}{|l|}{ Major } \\
\hline & Natural Science & 29 & 22.1 \\
\hline & Social Science & 102 & 77.9 \\
\hline \multicolumn{4}{|l|}{ Area } \\
\hline & Bali and Nusa Tenggara & 1 & .7 \\
\hline & Borneo & 12 & 9 \\
\hline & Celebes & 2 & 1.5 \\
\hline & Java & 114 & 85.1 \\
\hline & Sumatra & 4 & 3 \\
\hline & None & 1 & .7 \\
\hline \multicolumn{4}{|l|}{ GPA } \\
\hline & $3,00-4,00$ & 125 & 95.4 \\
\hline & $2,00-2,99$ & 5 & 3.8 \\
\hline & $1,00-1,99$ & 1 & .8 \\
\hline \multicolumn{4}{|c|}{$\begin{array}{l}\text { Participate in other } \\
\text { activities outside of college }\end{array}$} \\
\hline & Yes & 95 & 72.5 \\
\hline & No & 36 & 27.5 \\
\hline
\end{tabular}

Three hundred sixteen college students filled out the questionnaire; however, only 139 students met the study's criteria, and outlier analysis leaves only 131 participants; 25 male and 106 female students $(n=131, M=20.62, S D=1.686)$. The majority of participants are in 
their early adulthood and currently studying in semesters two to twelve. Most of them are from public universities in Indonesia, around Java, and majoring in social science. Generally, participants have a good GPA and are actively involved in other activities outside of universities, such as part-time and full-time work, organization, internship, and entrepreneurship (See Table 1).

\section{Instruments}

In this study, three scales are used to assess academic resilience, mindfulness, and selfcompassion. The scale used for academic resilience is The Academic Resilience Scale-30 (ARS-30) by Cassidy (2016) that the researchers adapted and has three dimensions; (1) perseverance with 14 items, (2) reflecting and adaptive help-seeking with nine items, (3) the negative affect and emotional response with seven items. However, after three tryouts, only 29 of 30 items in the adapted version met the minimum discrimination index value of 0.2 (Nunnally \& Bernstein, 1994). Item number 5 in the perseverance dimension must be deleted, leaving 13 items behind. The ARS-30 Cronbach Alpha was classified as very good with .902 (Nunnally \& Bernstein, 1994). Before responding to the scale, participants need to read an academic difficulty's schema in college and then imagine themselves in that situation. Participants choose one of five choices from (1) unlikely to (5) likely in each item.

The scale used to measure trait mindfulness is The Mindful Attention Awareness Scale (MAAS) by (Brown \& Ryan, 2003). MAAS is a unidimensional scale that measures a person's attention and awareness regarding the conditions happening here and now. MAAS consists of 15 items that was adapted by the researchers. The adapted version has very good reliability $(\alpha=.885)$, and all items have acceptable discrimination index values ranging from .214 - .753 (Nunnally \& Bernstein, 1994). Participants could choose one of six responses in each item: (1) almost never to (6) almost always.

The self-compassion scale (SCS) by Neff (2003) that has been adapted into Bahasa by Madita (2015) was used to measure self-compassion. The scale consists of 26 items with five choices from (1) almost never to (5) almost always and has very good reliability ( $\alpha=$ .94) (Nunnally \& Bernstein, 1994). SCS measures three pairs of opposing components: selfkindness and self-judgment (five items), common humanity and isolation (four items), and mindfulness and over-identification (four items). The discrimination index value ranged from .245 to .779 , and it meets the minimum acceptable DIV (Nunnally \& Bernstein, 1994).

\section{Data Analysis}

Descriptive and mediation analyses were carried out in this study. All data analyses using IBM SPSS Statistic 20 and PROCESS V3.5 (Hayes, 2013).

\section{Results}

Table 2 shows the participants' average score in the three variables is adequate. In mindfulness, the average score achieved is 55.66 from a maximum score of 90 . In the selfcompassion variable, the average score of participants is 85.73 from a maximum value of 130. In the academic resilience variable, the average score is 116.75 from a maximum value of 145 and is the highest of the three variables. 
Table 2

Descriptive Analysis of Mindfulness, Self-Compassion, and Academic Resilience

\begin{tabular}{lccc}
\hline & Mindfulness & Self-Compassion & Academic Resilience \\
\hline Mean & 55.66 & 85.73 & 116.76 \\
SD & 11.94 & 15.65 & 14.7 \\
Actual Range & $29-83$ & $47-119$ & $78-140$ \\
Possible Range & $15-90$ & $26-130$ & $29-145$ \\
\hline
\end{tabular}

The main results, as seen in Table 3, show that path $c$, which is mindfulness's direct effect on academic resilience, is positive and very significant $(\beta=.176, t(131)=3.391, p<.01$ $[.068, .284])$. But the extent of the variance of mindfulness on academic resilience is only $9.4 \%\left(F(1.130)=3.253, p<.01, R^{2}=.094\right)$. Path $a$ shows that mindfulness affects selfcompassion positively and very significantly $(\beta=.373, t(131)=6.424, p<.01[.258, .488])$, with the size of the effect reaching $26.8 \%\left(F(1.130)=11,575, p<.01, R^{2}=.268\right)$. Path $b$ shows that self-compassion affects the academic resilience of unprivileged students positively and very significantly as well $(\beta=.365, t(131)=4.728, p<.01[.212, .518])$. Finally, the mediation analysis of path $c^{\prime}$, which symbolizes the effect of mindfulness on academic resilience with the presence of a mediating role of self-compassion, shows that the direct effect is no longer significant $(\beta=.04, t(131)=.69, p>.05[-.074, .155])$.

Tabel 3

Regression Analysis for Mediation Model

\begin{tabular}{cccc}
\hline Path Notation & $\beta$ & $\mathrm{t}$ & $\mathrm{p}$ \\
\hline $\mathrm{a}$ & .373 & 4.728 & .000 \\
$\mathrm{~b}$ & .365 & 5.024 & .000 \\
$\mathrm{c}$ & .176 & 3.391 & .001 \\
$\mathrm{c}$ & .04 & .69 & .419 \\
& Effect & LLCI & ULCI \\
Direct Effect & .04 & -.074 & .155 \\
Indirect Effect & .136 & .07 & .218
\end{tabular}

Reference: Hayes, 2013.

This result means that the relationship between mindfulness and academic resilience is fully mediated by self-compassion, as shown in Figure 1. In other words, the presence of self-compassion improves the effect of mindfulness on academic resilience. The magnitude of the two variables' influence on academic resilience is $23.1 \%(F(1.130)=7.515, p<.01$, $R^{2}=.231$ ). The influence on academic resilience increased by $13.7 \%$, from $9.4 \%$ to $23.1 \%$.

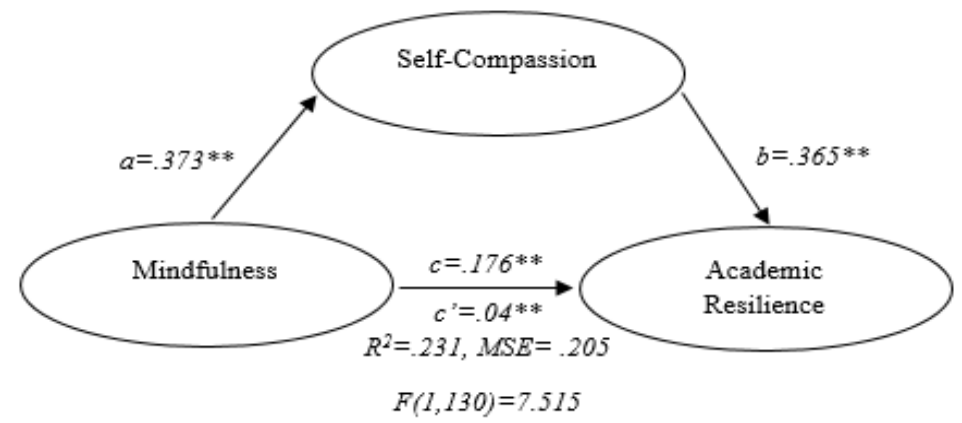

Figure 1. Self-compassion as a mediating factor 


\section{Discussion}

Generally, most participants in this study had adequate levels of mindfulness, academic resilience, and self-compassion. Furthermore, the main finding of this study shows selfcompassion fully mediates the role of mindfulness on the academic resilience of unprivileged college students in Indonesia. It means that being mindful indirectly increases the ability to bounce back and overcome college challenges. This indirect relationship is facilitated by the ability to feel compassion for oneself when faced with difficulties. This finding emphasizes the benefits of mindfulness and self-compassion in increasing academic resilience among high-risk populations prone to dropping out, specifically unprivileged college students.

Overall, resilience becomes critical to assist college students in managing academic demands, coping, and maintaining positive progress despite the pressures of study, work, and life (Caruana, Clegg, Ploner, \& Wood, 2011). Resilience can be strengthened through internal factors such as personality or resources (Ledesma, 2014) that effectively encourage individuals to respond to challenges (Graham, 2013). In this study, internal factors found to support academic resilience were mindfulness and self-compassion. The findings are consistent with previous research in other high-risk populations, such as veterinary students and pediatric residents, who face numerous challenges and high stress levels during their studies (McArthur et al., 2017; Olson, Kemper, \& Mahan, 2015). In Indonesia itself, researchers find it difficult to find research that addresses this topic. Therefore, this study adds new findings that prove and explain the relationship between the three variables.

Mindfulness helps students to realize and accept experiences as they are (McArthur et al., 2017); it is an ability to be conscious without judging the current experience (Brown, Goodman, Ryan, \& Anālayo, 2016). It allows individuals to experience a condition without being carried away by their immediate reaction (Kang, Gruber, \& Gray, 2013). Mindfulness helps individuals realize their tendency to react in a certain way to prevent themselves from being impulsive (McArthur et al., 2017). However, the ability to be mindful will not reduce the negative thoughts that individuals feel. These thoughts will still appear, but they will no longer control the individuals to reduce the negative impact (Frewen, Evans, Maraj, Dozois, \& Partridge, 2008). In this study, there is uniqueness found in how mindfulness affects the academic resilience of participants. Suppose studies on other high-risk students show that mindfulness can directly affect and increase academic resilience (McArthur et al., 2017; Olson et al., 2015). In this study, the direct effect of mindfulness on academic resilience is relatively small, with only $9.4 \%$. Therefore, mindfulness can no longer directly affect academic resilience when the self-compassion variable is added as a mediator. It means the effect of mindfulness is explained better with the presence of self-compassion, in which the effect size increases from $9.4 \%$ to $23.1 \%$.

The main finding of this study seems to be closely related to the economic condition possessed by the participants. Living in poverty has various disadvantages that could increase life stress and dampen an individual's resilience (Evans \& Kim, 2013). Unprivileged students often grew up with comments about how poor, inadequate, dirty, and stupid they are (Brown, 1999). All this experience forms a negative judgment because a person will usually value himself based on the shared belief he finds and gathers from the people in his environment (Erikson, 1980). In addition, negative life experiences related to poverty make it easier for unprivileged students to perceive they would experience or get negative results in many situations and challenges (Chen \& Matthews, 2001). Therefore, in college, unprivileged college students could quickly feel uncomfortable and intimidated by the challenges that exist (Aries \& Seider, 2005). 
Self-compassion could help unprivileged college students to treat themselves better despite their negative life circumstances. Self-compassion is openness, not avoiding or trying to get away from pain, and makes individuals grow a desire to alleviate suffering and heal themselves by being kind to themselves (Neff, 2003). According to the previous study's findings, self-compassion helps people deal with difficult situations such as failure, rejection, and even shame (Leary et al., 2007). Self-compassion helps individuals accept all their characters, behaviors, and conditions truthfully (Leary et al., 2007). It means that even though individuals are aware of their shortcomings, they will not be defensive or feel sorry for themselves. They accept it and acknowledge their responsibility when experiencing failure without being in excessive guilt and self-criticism. Self-compassion creates a safe emotional space for people to see their patterns of maladaptive thoughts, feelings, and behaviors without being afraid or punishing themselves excessively. In the end, this allows individuals to assess a condition more objectively to make the right decision for their problem (Leary et al., 2007). In an educational context, students with good self-compassion will be able to accept their inadequacy and failures, so they easily forgive themselves and are more motivated to improve their academic performance (Breines \& Chen, 2012).

Individuals need to realize that they are suffering before treating themselves with compassion, as a person cannot heal the wounds that he cannot feel (Neff, 2011). Therefore, according to the Buddhist perspective, self-compassion arises in the presence of mindfulness (Hollis-Walker \& Colosimo, 2011). Previous research has also demonstrated a link between self-compassion and mindfulness (Baer et al., 2012; Hollis-Walker \& Colosimo, 2011; Van Dam, Sheppard, Forsyth, \& Earleywine, 2011). To treat oneself with compassion when experiencing painful thoughts and feelings, individuals need to observe and acknowledge the existence of their emotions without avoiding or overvaluing them (Neff, 2003). As a result, in this study, mindfulness plays a role in strengthening unprivileged college students' self-compassion, which leads to improved academic resilience during their college experience.

This study contributes to investigating trainable qualities (mindfulness and selfcompassion) in improving the academic resilience of unprivileged college students. In Indonesia, based on a literature study conducted by the researchers, only one study tries to develop and test the effectiveness of resilience programs for unprivileged college students (Wedyaswari, Cahyadi, Susiati, \& Yuanita, 2019). However, the program uses the Cognitive Behavioral Therapy (CBT) approach and has not increased unprivileged college students' academic resilience. As a result, a new self-development intervention for unprivileged college students in Indonesia may be developed based on this study's findings to confirm the benefits of mindfulness and self-compassion in improving academic resilience.

There are some limitations to this study. First, one item from the academic resilience scale does not meet the minimum standard of difference index value even though the researchers have revised it three times. Therefore, we recommend that the following study improve this item to complete the adaptation of this scale. Second, this study's sample size is relatively small, with more female participants than males. In addition, most unprivileged students in this study are from Java, so the generalization of the study result is limited. The following research should recruit more participants with a more balanced gender and regions proportion in Indonesia to ensure study results. Third, resilience is a quality that continues to develop by personal experience from time to time. According to years of research, there was no significant difference in the level of resilience of participants. It seems this is because the participants are still at the same developmental stage and challenges. Therefore, it is interesting to conduct longitudinal research in different developmental stages to test the relationship dynamics between the three variables. 


\section{Conclusion}

Self-compassion fully mediates the relationship between mindfulness and academic resilience among unprivileged college students in Indonesia. This finding means that mindfulness cannot directly increase participants' academic resilience without the role of self-compassion. Unprivileged college students with good academic resilience will have a higher chance of conquering academic challenges and completing their studies. Nevertheless, the results of this study still need to be expanded with further research by improving the limitations of this study.

\section{References}

Anggraeni, D. T., \& Kurniawan, N. I. (2012). Self-compassion and satisfaction with life: A preliminary study on Indonesian college students. [Paper presentation]. 3rd International Conference on Behavioral, Cognitive and Psychological Sciences, Bangkok, Thailand.

Aries, E., \& Seider, M. (2005). The interactive relationship between class identity and the college experience: The case of lower income students. Qualitative Sociology, 28, 419433. https://doi.org/10.1007/s11133-005-8366-1

Baer, R. A., Lykins, E. L. B., \& Peters, J. R. (2012). Mindfulness and self-compassion as predictors of psychological wellbeing in long-term meditators and matched nonmeditators. The Journal of Positive Psychology, 7(3), 230-238. https://doi.org/10.1080/17439760.2012.674548

Barnard, L. K., \& Curry, J. F. (2011). Self-compassion: Conceptualizations, correlates, \& interventions. Review of General Psychology, 15(4), 289-303. https://doi.org/10.1037/a0025754

Benada, N., \& Chowdhry, R. (2017). A Correlational study of happiness, resilience and mindfulness among nursing student. Indian Journal of Positive Psychology, 8(2), 105107.

Bishop, S. R., Lau, M., Shapiro, S., Carlson, L., Anderson, N. D., Carmody, J., ... Devins, G. (2004). Mindfulness: A proposed operational definition. Clinical Psychology: Science and Practice, 11(3), 230-241. https://doi.org/10.1093/clipsy.bph077

Breines, J. G., \& Chen, S. (2012). Self-compassion increases self-improvement motivation. Personality \& Social Psychology Bulletin, 38(9), 1133-1143. https://doi.org/10.1177/0146167212445599

Broderick, P. C., \& Jennings, P. A. (2012). Mindfulness for adolescents: A promising approach to supporting emotion regulation and preventing risky behavior. New Directions for Youth Development, 2012(136), 111-126. https://doi.org/10.1002/yd.20042

Brown, B. (1999). Soul without shame: A guide to liberating yourself from the judge within. Shambhala Publication, Inc.

Brown, K. W., Goodman, R. J., Ryan, R. M., \& Anālayo, B. (2016). Mindfulness enhances episodic memory performance: Evidence from a multimethod investigation. PloS One, 11(4), e0153309. https://doi.org/10.1371/journal.pone.0153309

Brown, K. W., \& Ryan, R. M. (2003). The benefits of being present: Mindfulness and its role in psychological well-being. Journal of Personality and Social Psychology, 84(4), 822-848. https://doi.org/10.1037/0022-3514.84.4.822 
Brown, K. W., Ryan, R. M., \& Creswell, J. D. (2007). Mindfulness: Theoretical foundations and evidence for its salutary effects. Psychological Inquiry, 18(4), 211-237. https://doi.org/10.1080/10478400701598298

Cahalan, M. W., Perna, L. W., Addison, M., Murray, C., Patel, P. R., \& Jiang, N. (2020). Indicators of higher education equity in the United States. The Pell Institute.

Caruana, V., Clegg, S., Ploner, J., \& Wood, R. (2011). Promoting students' 'resilient thinking' in diverse higher education learning environments. Leeds Metropolitan University.

Cassidy, S. (2016). The Academic Resilience Scale (ARS-30): A new multidimensional construct measure. Frontiers in Psychology, 7, 1787. https://doi.org/10.3389/fpsyg.2016.01787

Chen, E., \& Matthews, K. A. (2001). Cognitive appraisal biases: An approach to understanding the relation between socioeconomic status and cardiovascular reactivity in children. Annals of Behavioral Medicine, 23(2), 101-111. https://doi.org/10.1207/S15324796ABM2302_4

Cilesiz, S., \& Drotos, S. M. (2016). High-poverty urban high school students' plans for higher education: Weaving their own safety nets. Urban Education, 51(1), 3-31. https://doi.org/10.1177/0042085914543115

Duncan, G. J., \& Magnuson, K. (2013). The long reach of early childhood poverty. In: Yeung WJ., Yap M. (eds) Economic stress, human capital, and families in Asia. Quality of Life in Asia, vol 4. https://doi.org/10.1007/978-94-007-7386-8_4

Engle, J., \& Tinto, V. (2008). Moving beyond access: College success for low-income, firstgeneration students. The Pell Institute.

Erikson, E. H. (1980). Identity and the life cycle. W W Norton \& Co.

Evans, G. W., \& Kim, P. (2013). Childhood poverty, chronic stress, self-regulation, and coping. Child Development Perspectives, 7(1), 43-48. https://doi.org/10.1111/cdep.12013

Frewen, P. A., Evans, E. M., Maraj, N., Dozois, D. J. A., \& Partridge, K. (2008). Letting go: Mindfulness and negative automatic thinking. Cognitive Therapy and Research, 32(6), 758-774. https://doi.org/10.1007/s10608-007-9142-1

Galante, J., Dufour, G., Vainre, M., Wagner, A. P., Stochl, J., Benton, A., ... Jones, P. B. (2018). A mindfulness-based intervention to increase resilience to stress in university students (the Mindful Student Study): A pragmatic randomised controlled trial. The Lancet Public Health, 3(2), e72-e81. https://doi.org/10.1016/S2468-2667(17)30231-1

Germer, C. (2009). The mindful path to self-compassion. The Guilford Press.

Graham, L. (2013). Bouncing back: Rewiring your brain for maximum resilience and wellbeing. New World Library.

Hayes, A. F. (2013). Introduction to mediation, moderation, and conditional process analysis: A regression-based approach. Guilford Press.

Hollis-Walker, L., \& Colosimo, K. (2011). Mindfulness, self-compassion, and happiness in non-meditators: A theoretical and empirical examination. Personality and Individual Differences, 50(2), 222-227. http://doi.org/10.1016/j.paid.2010.09.033

Javanbakht, A., King, A. P., Evans, G. W., Swain, J. E., Angstadt, M., Phan, K. L., \& Liberzon, I. (2015). Childhood Poverty Predicts Adult Amygdala and Frontal Activity and Connectivity in Response to Emotional Faces. Frontiers in Behavioral Neuroscience, 9, 154. https://doi.org/10.3389/fnbeh.2015.00154

Jerrim, J., \& Macmillan, L. (2015). Income inequality, intergenerational mobility, and the great gatsby curve: Is education the key? Social Forces, 94(2), 505-533. https://doi.org/10.1093/sf/sov075 
Kang, Y., Gruber, J., \& Gray, J. R. (2013). Mindfulness and de-automatization. Emotion Review, 5(2), 192-201. https://doi.org/10.1177/1754073912451629

Keye, M. D., \& Pidgeon, A. M. (2013). Investigation of the relationship between resilience, mindfulness, and academic self-efficacy. Open Journal of Social Sciences, 1(6), 1-4. https://doi.org/10.4236/jss.2013.16001

Lau, M. A., Bishop, S. R., Segal, Z. V, Buis, T., Anderson, N. D., Carlson, L., ... Devins, G. (2006). The Toronto Mindfulness Scale: Development and validation. Journal of Clinical Psychology, 62(12), 1445-1467. https://doi.org/10.1002/jclp.20326

Leary, M. R., Tate, E. B., Adams, C. E., BattsAllen, A., \& Hancock, J. (2007). Selfcompassion and reactions to unpleasant self-relevant events: The implications of treating oneself kindly. Journal of Personality and Social Psychology, 92(5), 887-904. https://doi.org/10.1037/0022-3514.92.5.887

Ledesma, J. (2014). Conceptual frameworks and research models on resilience in leadership. SAGE Open, 4(1), 1-8. https://doi.org/10.1177/2158244014545464

MacBeth, A., \& Gumley, A. (2012). Exploring compassion: A meta-analysis of the association between self-compassion and psychopathology. Clinical Psychology Review, 32(6), 545-552. https://doi.org/10.1016/j.cpr.2012.06.003

Madita, A. S. (2015). Hubungan antara self-compassion dengan college self-efficacy pada mahasiswa tahun pertama (The relationship bertwee self-compassion with college selfeffcacy among first year undergraduate students). Unpublished Undergraduate Thesis. Universitas Indonesia.

Madita, A. S., \& Widyasari, P. (2020). Relationship between self-compassion and college self-efficacy among rirst-year college students. [Paper presentation]. 3rd International Conference on Intervention and Applied Psychology (ICIAP 2019) and the 4th Universitas Indonesia Psychology Symposium for Undergraduate Research (UIPSUR 2019), Jakarta, Indonesia. https://doi.org/10.2991/assehr.k.201125.001

Mapel, T. (2012). Mindfulness and education: Students' experience of learning mindfulness in a tertiary classroom. New Zealand Journal of Educational Studies, 47(1), 19-32.

Martin, A. J., \& Marsh, H. W. (2006). Academic resilience and its psychological and educational correlates: A construct validity approach. Psychology in the Schools, 43(3), 267-281. https://doi.org/10.1002/pits.20149

Masten, A. S. (2014). Global perspectives on resilience in children and youth. Child Development, 85(1), 6-20. https://doi.org/10.1111/cdev.12205

Mathad, M. D., Pradhan, B., \& Rajesh, S. K. (2017). Correlates and predictors of resilience among baccalaureate nursing students. Journal of Clinical and Diagnostic Research, 11(2), JC05-JC08. https://doi.org/10.7860/JCDR/2017/24442.9352

McArthur, M., Mansfield, C., Matthew, S., Zaki, S., Brand, C., Andrews, J., \& Hazel, S. (2017). Resilience in veterinary students and the predictive role of mindfulness and self-compassion. Journal of Veterinary Medical Education, 44(1), 106-115. https://doi.org/10.3138/jvme.0116-027R1

Morales, E. E. (2014). Learning from success: How original research on academic resilience informs what college faculty can do to increase the retention of low socioeconomic status students. International Journal of Higher Education, 3(3), 92-102. https://doi.org/10.5430/ijhe.v3n3p92

National Research Council. (2002). Learning and understanding: Improving advanced study of mathematics and science in U.S. high schools. In and P. C. C. Jerry P. Gollub, Meryl W. Bertenthal, Jay B. Labov (Ed.). Learning and Understanding. The National Academic Press. https://doi.org/10.17226/10129

National Survey of Student Engagement. (2006). Engaged learning: Fostering success for 
all students. Center for Postsecondary Research School of Education Indiana University Bloomington.

Neff, K. (2003). Self-compassion: An alternative conceptualization of a healthy attitude toward oneself. Self and Identity, 2(2), 85-101. https://doi.org/10.1080/15298860309032

Neff, K. D. (2011). Self-compassion, self-esteem, and well-being. Social and Personality Psychology Compass, 5(1), 1-12. https://doi.org/10.1111/j.1751-9004.2010.00330.x

Neff, K. D., \& Dahm, K. A. (2015). Self-compassion: What it is, what it does, and how it relates to mindfulness. In B. D. Ostafin, M. D. Robinson, \& B. P. Meier (Eds.). Handbook of mindfulness and self-regulation (pp. 121-137). Springer Science + Business Media. https://doi.org/10.1007/978-1-4939-2263-5_10

Neff, K. D., \& McGehee, P. (2010). Self-compassion and psychological resilience among adolescents and young adults. Self and Identity, 9(3), 225-240. https://doi.org/10.1080/15298860902979307

Niemiec, R. M. (2005). The expansion of mindfulness meditation. PsycCRITIQUES, 50(23), 1-5. https://doi.org/10.1037/051499

Nunnally, J., \& Bernstein, I. (1994). Psychometric theory, 3rd Ed. McGraw-Hill.

Nyklíček, I., Dijksman, S. C., Lenders, P. J., Fonteijn, W. A., \& Koolen, J. J. (2014). A brief mindfulness based intervention for increase in emotional well-being and quality of life in percutaneous coronary intervention (PCI) patients: The MindfulHeart randomized controlled trial. Journal of Behavioral Medicine, 37(1), 135-144. https://doi.org/10.1007/s10865-012-9475-4

Olson, K., Kemper, K. J., \& Mahan, J. D. (2015). What factors promote resilience and protect against burnout in first-year pediatric and medicine-pediatric residents? Journal of Evidence-Based Complementary \& Alternative Medicine, 20(3), 192-198. https://doi.org/10.1177/2156587214568894

Ramler, T. R., Tennison, L. R., Lynch, J., \& Murphy, P. (2016). Mindfulness and the college transition: The efficacy of an adapted mindfulness-based stress reduction intervention in fostering adjustment among first-year students. Mindfulness, 7(1), 179-188. https://doi.org/10.1007/s12671-015-0398-3

Richardson, G. E. (2002). The metatheory of resilience and resiliency. Journal of Clinical Psychology, 58(3), 307-321. https://doi.org/10.1002/jclp.10020

Rogers, H. B. (2013). Mindfulness meditation for increasing resilience in college students. Psychiatric Annals, 43(12), 545-548. https://doi.org/10.3928/00485713-20131206-06

Salam, M., Awang Iskandar, D. N., Ibrahim, D. H. A., \& Farooq, M. S. (2019). Service learning in higher education: A systematic literature review. Asia Pacific Education Review, 20(4), 573-593. https://doi.org/10.1007/s12564-019-09580-6

Shonin, E., Van Gordon, W., \& Griffiths, M. D. (2014). The emerging role of Buddhism in clinical psychology: Toward effective integration. Psychology of Religion and Spirituality, 6(2), 123-137. https://doi.org/10.1037/a0035859

Sünbül, Z. A. (2019). The relationship between mindfulness and resilience among adolescents: Mediating role of self-compassion and difficulties in emotion regulation. Personality and Individual Differences, 139(1), 337-342. https://doi.org/10.1016/j.paid.2018.12.009

Taren, A. A., Gianaros, P. J., Greco, C. M., Lindsay, E. K., Fairgrieve, A., Brown, K. W., ... Creswell, J. D. (2015). Mindfulness meditation training alters stress-related amygdala resting state functional connectivity: A randomized controlled trial. Social Cognitive and Affective Neuroscience, 10(12), 1758-1768. https://doi.org/10.1093/scan/nsv066 
Thompson, R. W., Arnkoff, D. B., \& Glass, C. R. (2011). Conceptualizing mindfulness and acceptance as components of psychological resilience to trauma. Trauma, Violence \& Abuse, 12(4), 220-235. https://doi.org/10.1177/1524838011416375

Van Dam, N. T., Sheppard, S. C., Forsyth, J. P., \& Earleywine, M. (2011). Self-compassion is a better predictor than mindfulness of symptom severity and quality of life in mixed anxiety and depression. Journal of Anxiety Disorders, 25(1), 123-130. https://doi.org/10.1016/j.janxdis.2010.08.011

Verplanken, B., \& Fisher, N. (2014). Habitual worrying and benefits of mindfulness. Mindfulness, 5(5), 566-573. https://doi.org/10.1007/s12671-013-0211-0

Wahyudi, A., Suardiman, S. P., \& Rosada, U. D. (2020). The profile of Bidik Misi grantee's resilience. Proceedings of the 3rd International Conference on Education Innovation (ICEI 2019). https://doi.org/10.2991/icei-19.2019.5

Wedyaswari, M., Cahyadi, S., Susiati, E., \& Yuanita, R. A. (2019). Rancangan pendampingan "4 skills of resilience" untuk pengembangan resiliensi bidang akademik pada mahasiswa Bidik Misi (The design of "4 skills of resilience" to develop academic resilience among awardee Bidik Misi). Journal of Psychological Science and Profession, 3(2), 89-98. https://doi.org/10.24198/jpsp.v3i2.21874

World Bank. (2014). Tertiary education in Indonesia: Directions for policy. Retrieved from https://openknowledge.worldbank.org/handle/10986/20024

Yamada, K., \& Victor, T. L. (2012). The impact of mindful awareness practices on college student health, well-being, and capacity for learning: A pilot study. Psychology Learning \& Teaching, 11(2), 139-145. https://doi.org/10.2304/plat.2012.11.2.139 